\title{
ECCRINE POROCARCINOMA OF SCALP WITH MULTIPLE SECONDARIES ARISING AFTER RADIOTHERAPY FOR HYPOPHARYNGEAL CARCINOMA
}

Md. Naveed Ahmed ${ }^{1}$, M. Mahendra Kumar², S. Muneeruddin Ahmed ${ }^{3}$, N. Venkatram Reddy4, Laxminarayana ${ }^{5}$

\section{HOW TO CITE THIS ARTICLE:}

Md. Naveed Ahmed, M. Mahendra Kumar, S. Muneeruddin Ahmed, N. Venkatram Reddy, Laxminarayana. "Eccrine Porocarcinoma of Scalp with Multiple Secondaries Arising after Radiotherapy or Hypopharyngeal Carcinoma". Journal of Evolution of Medical and Dental Sciences 2014; Vol. 3, Issue 27, July 07;

Page: 7574-7578, DOI: $10.14260 /$ jemds/2014/2938

\begin{abstract}
Malignant eccrine poroma is a rare skin adnexal tumor arising from the eccrine sweat glands. It arises from different sites in the body lower extremities, palmand trunk. Porocarcinoma from scalp is rare and we are presenting a case of porocarcinoma arising from the scalp post radiotherapy for the hypo-pharyngeal tumor. The tumor was presented with multiple secondaries in brain and lung.
\end{abstract}

KEYWORDS: Poro-carcinoma, post radiotherapy, Hypo pharyngeal carcinoma, eccrine, metastases.

CASE REPORT: A 55years old male presented with multiple swellings over the frontoparietal region of the scalp (figure-1).The swellings are multiple, bosselated, nodular, erythematous, firm, nontender, non- fluctuantand few are polypoidal ulcerating with bleeding on touch. Posterior triangle group of lymph nodes are palpable on left side. The patient was previously diagnosed as a case of carcinoma pyriform fossa left side of stage 3and undergone radiotherapy 2years back and the growth regressed. At present no growth is seen in the larynx. CT scan of brain and chest showed muliple secondaries in the right temporal lobe, right cerebellar hemisphere, frontal and parietal bones, both lungs and hilar lymphnodes (figure 2, 3, 4).

Biopsy was taken from the lesion over the scalp.The dermis showed round to oval cells arranged in nests and islands. The cells have moderate amount of cytoplasm, moderately pleomorphic hyper-chromatic to vesicular nuclei with nucleoli. Brisk mitotic activity and necrosis is present. Few cells show cytoplasmic clearing (fig. 5, 6).As the patient general condition was poor with metastases palliative treatment was given with chemotherapy.

DISCUSSION: Eccrine Porocarcinoma is a rare neoplasm arising from eccrine sweat gland. ${ }^{1}$ The incidence is $0.005 \%$ to $0.01 \%$ of all skin tumours. It was first described by Pinkus and Mehregan in 1963 as an "Epidermotropic eccrine carcinoma". It has also been described as malignant hidroacanthoma simplex, sweat gland carcinoma, malignant intra-epidermal eccrine poroma, eccrine poro-epithelioma, dysplastic poroma, malignant syringoacanthoma and porocarcinoma. ${ }^{2}$ It originates from intra-epidermal and upper dermal eccrine ducts.

It arises denovo or from malignant transformation of eccrine poroma, nevus sebaceous, chronic lymphatic leukemia and actinic lesions. It also arises after radiotherapy. ${ }^{3}$ Clinical differential diagnosis include cutaneous squamous cell carcinoma, basal cell carcinoma, cutaneous lymphoma, Paget's disease, Bowen's disease, cutaneous metastases, amelanotic melanoma, pyogenic granuloma. 4,5 


\section{CASE REPORT}

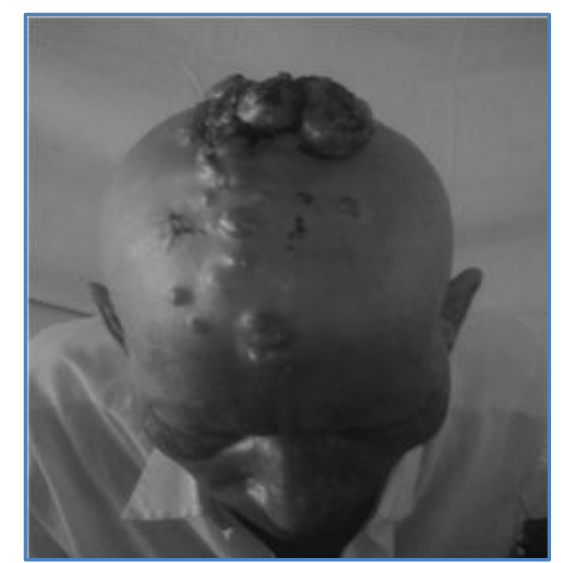

Fig. 1: Multiple swellings over the frontoparietal region

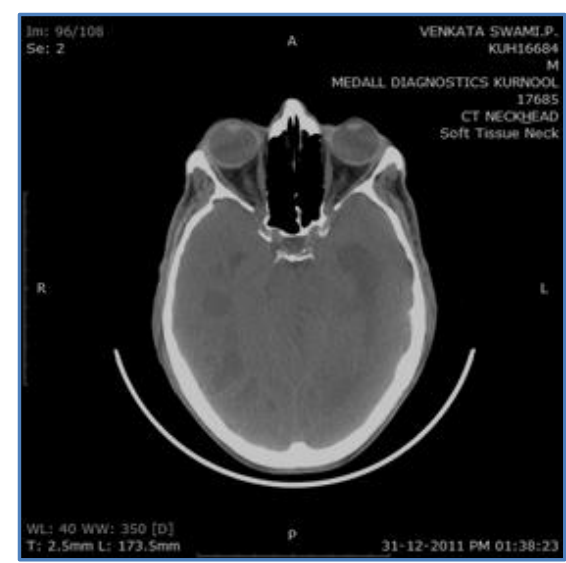

Fig. 2: CT Scan of the brian showing multiple metastases in the parietal and occipital regions

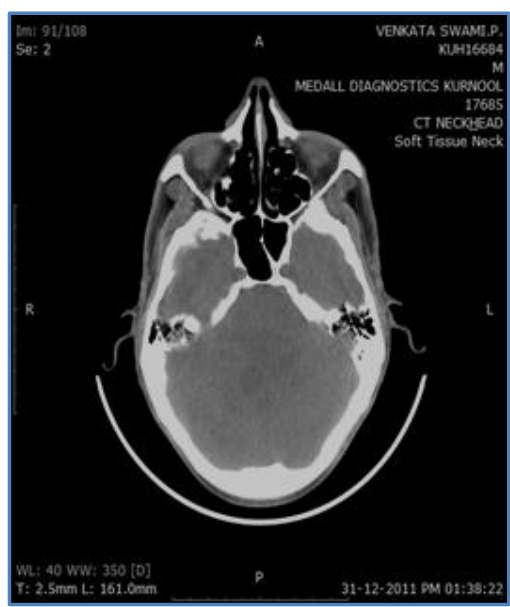

Fig. 3: CT Scan of brain showing metastases in the cerebellum

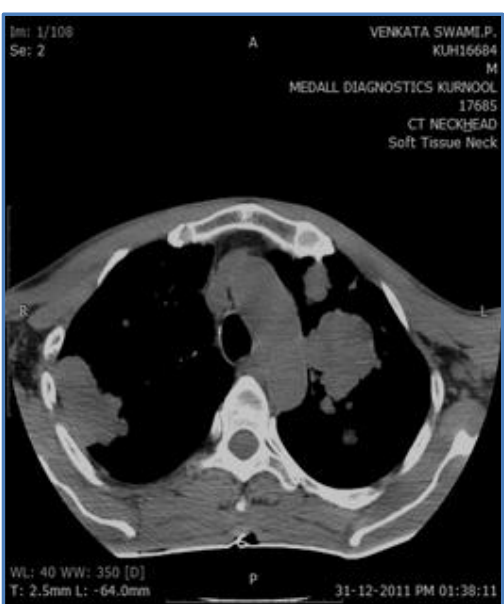

Fig. 4: CT scan of lung showing multiple metastases

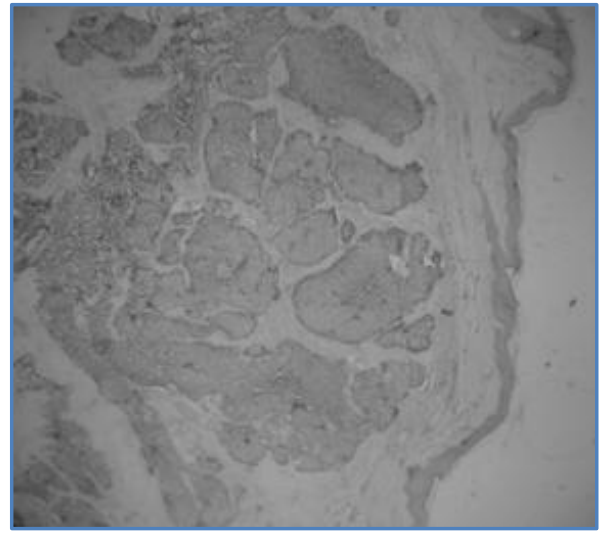

Fig. 5: Tumour infiltrating the dermis showing round to oval cells arranged in nests and islands 
Fig. 6: High power view with cells having moderately pleomorphic, hyper-chromatic to vesicular nuclei with nucleoli. Brisk mitotic activity and necrosis is present.

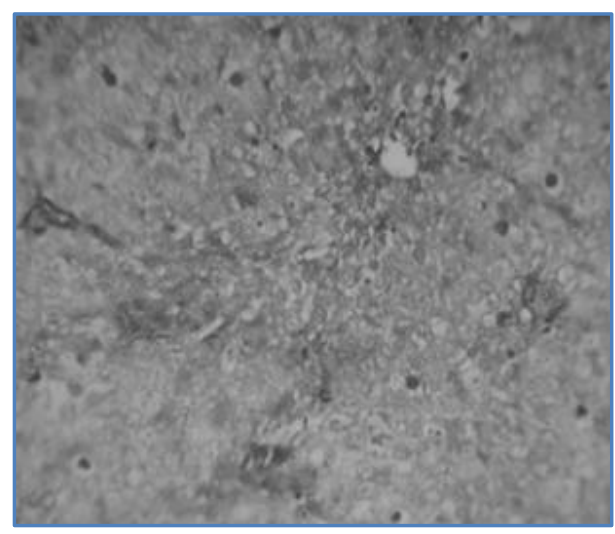

Figure 6

It is usually located in the lower extremities (44\%) of cases but rarely seen in scalp, face and ear $(<20 \%)$, upper extremities (11\%), trunk and abdomen (9\%). ${ }^{6}$ No sex predilection is seen. The tumour will present as a verucous plaque, polypoidal growth and ulcerative lesion. Our patient presented as an ulcerative lesion which bleeds on touch. Regional lymphnode metastases and systemic metastases occur in $19 \%$ and $11 \%$ of cases.

This patient presented with both lymphnode and systemic metastases to lung, brain and bone. Tumours show multiple connections to the epidermisand a pre-exsisting benign eccrine poroma may be present. The tumour infiltrates the dermis and the subcutaneous tissues in nests and lobules composed of relatively small cells that do not have a basaloid appearance 6 .Ductal differientiation is necesaary for the diagnosis to be made.This is demonstared by the use of immunohistochemical stains carcinoembryonic antigen (CEA) and epithelial membrane antigen (EMA).4, 6

The pathogenesis of this lesion has not been elucidated, but the occurrence of eccrine poroma after trauma or radiation exposure has been documented in the literature. Although the development of porocarcinoma in a traumatized area is reported, the occurrence of the malignant eccrine poroma after radiotherapy has not been described, but other forms of radiation-induced skin cancer is well known. Radiation-induced skin cancer may be associated with radiotherapy or occupational exposure. Several factors seem to influence the risk of radiation-induced cancer, such as total dose, young age at the time of irradiation, nature of irradiated tissue, and associated disease. This case suggests that malignant eccrine poroma may occur following radiotherapy.

Recommended treatment is wide local excision with regional lymph node dissection if involved.4,5,6 Management of the patient with clinically negative nodes remains controversial. Chang et al. ${ }^{11}$ report the efficacy of lympho-scintigraphy with sentinel lymph node biopsy in identifying microscopic metastases of EP in primary lesions arising in the head and neck. There are no data to support the use of adjuvant therapy(both radiotherapy and chemotherapy) in the management of EP.

Plunkett et al. ${ }^{7}$ have reported a marked symptomatic and radiological response to treatment with docetaxel in a female renal transplant patient aged 45years with a metastatic EP resistant to epirubicin. Oudit et al. ${ }^{8}$ have mentioned use of Melphalan, intra-arterial infusion of 5-flurouracil and 
hyperthermia. Perilesional injection of interferon-alpha and interleukin-2 has been reported to produce a partial response.Arslan ${ }^{9}$ has mentioned use of docetaxel, interferon-alpha $2 \mathrm{a}$ and isotretinoin. Dasilva ${ }^{10}$ have reported a successful outcome with post-operative radiotherapy.

More than 100 cases of porocarcinoma have been described in literature, of which less than 10 cases have been of scalp porocarcinoma. ${ }^{6}$ There is no case reported in literature of porocarcinoma on the fronto-parietal region post radiotherapy to the hypo pharyngeal cancer with multiple systemic metastases.

CONCLUSION: Eccrineporocarcinoma in the scalp post radiotherapy is rare with multiple metastases. The treatment for metastatic eccrine poroma is not standardized. Neither chemotherapy nor radiotherapy was of much clinical benefit to patient. Our patient presented lately with multiple metastases and chemotherapy is not of much use. So any patient post radiotherapy was monitored regularly for radiation induced tumours. If porocarcinoma is diagnosed then wide surgical excision is planned without any delay.

ACKNOWLEDGEMENT: We Thank the Superintendent and Principal Government General Hospital and KurnoolMedical College, Kurnool respectively for permitting us to undertake the study. We thank all theresidents and nursing staff for taking care of the patients during immediate post -operative period.

\section{REFERENCES:}

1. A M Ritter, R S Graham, B Amaker, W C Broaddus, H F Young. Intracranial extension of an eccrine porocarcinoma. Case report and review of the literature. Journal Of Neurosurgery (1999) Volume: 90, Issue: 1, P 138-140.

2. E. Ferri, G.A. Iaderosa \& E. Armato: Metastasizing Eccrine Porocarcinoma of the Nose: CaseReport with Immunohisto chemical Study and Review of the Literature. The Internet Journal of Otorhinolaryngology. 2008 Volume 7 Number 2.

3. RustuKose, Y Kenan Coban, HarunCiralik. Eccrine porocarcinoma arising from pre-existing eccrine poroma of the scalp after radiotherapy for cervical cancer. Dermatology Online Journal $12(6): \mathrm{p} 18$.

4. Ugo Marone, CorradoCaracò, Anna Maria Anniciello et al. Metastatic eccrine porocarcinoma: report of a case and review of the literature. World Journal of Surgical Oncology 2011 9:32.

5. Fabiane Andrade Mulinari-Brenner1, Maira Mitsue Mukai2, Carlos Augusto Silva Bastos3, Ezio Augusto Amaral Filho4, Jesus Rodriguez Santamaria5, José Fillus Neto6Eccrine porocarcinoma: report of four cases and literature review; An Bras Dermatol. 2009; 84(5): 519-23..

6. Rana RE, Verma SS, Puri VA, Baliarsing AS. Sweat gland tumor (Eccrine Porocarcinoma) of scalp: A rare tumor. Indian J PlastSurg 2005;38:51-3.

7. Plunkett TA, Hanby AM, Miles DW, Rubens RD: Metastatic eccrine porocarcinoma: response to docetaxel (Taxotere) chemotherapy. Ann Oncol 2001; 12:411-414.

8. Oudit D, Ellabban M, Vuppalapati G, Stringfellow H, Korashi A. Porocarcinoma? PlastReconstr Surg 2004;113:2216-7.

9. Arslan E, Tatar C, Aksy A, Tutuner N. Denovo malignant eccrine poroma of the nose: A review of the midface as a location. Plast Reconstr Surg 2004; 113:2227-9. 


\section{CASE REPORT}

10. Dasilva MF, Terek R, Weiss AP. Malignant eccrine poroma of the hand. A case report. J Hand Surg 1997; 22: 511-4.

11. Chang AS, Busam K, Kraus DH: Applicability of lymphoscintigraphy with sentinel node biopsy to eccrine carcinoma of the head and neck. Head Neck 2003; 25(10):879-882.

\section{AUTHORS:}

1. Md. Naveed Ahmed

2. M. Mahendra Kumar

3. S. Muneeruddin Ahmed

4. N. Venkatram Reddy

5. Laxminarayana

\section{PARTICULARS OF CONTRIBUTORS:}

1. Professor, Department of ENT, GMC, Hyderabad.

2. Assistant Professor, Department of ENT, KMC, Kurnool.

3. Professor, Department of ENT, KMC, Kurnool.

4. Associate Professor, Department of ENT, OMC, Hyderabad.
5. Senior Resident, Department of ENT, KMC, Kurnool.

\section{NAME ADDRESS EMAIL ID OF THE} CORRESPONDING AUTHOR:

Dr. S. Muneeruddin Ahmed, 44/118, Prakashnagar, Kurnool-518004, Andhra Pradesh.

Email: ahmedmurient@gmail.com

Date of Submission: 26/06/2014.

Date of Peer Review: 27/06/2014.

Date of Acceptance: 28/06/2014.

Date of Publishing: 07/07/2014. 